\title{
Standard Radiation Dosimetry Models: What Interventional Radiologists Need to Know
}

\author{
Linzi Arndt Webster ${ }^{1} \quad$ Alexander Villalobos ${ }^{1} \quad$ Bill S. Majdalany ${ }^{1} \quad$ Zachary L. Bercu $^{1} \quad$ Ripal T. Gandhi ${ }^{2}$ \\ Nima Kokabi, MD, FRCPC ${ }^{1}$ \\ ${ }^{1}$ Division of Interventional Radiology and Image-Guided Medicine, \\ Department of Radiology and Imaging Sciences, Emory University School \\ of Medicine, Emory University School of Medicine, Atlanta, Georgia \\ 2 Miami Cardiac and Vascular Institute, Miami Cancer Institute, Miami, FL

\begin{abstract}
Address for correspondence Nima Kokabi, MD, Division of Interventional Radiology and Image-Guided Medicine, Department of Radiology and Imaging Sciences, Emory University School of Medicine, 1364 Clifton Rd NE, Atlanta, GA 30322

(e-mail: Nima.Kokabi@emory.edu).
\end{abstract}

Semin Intervent Radiol 2021;38:405-411

\begin{abstract}
Keywords

- Y90

- Dosimetry

- Partition Model

- BSA model

- MIRD model

- Yttrium-90

- Radioembolization

Thoughtful and accurate dosimetry is critical to obtain the safest and most efficacious yttrium-90 (Y90) radioembolization of primary and secondary liver cancers. Three dosimetry models are currently used in clinical practice, namely, body surface area model, medical internal radiation dose model, and the partition model. The objective of this review is to briefly outline the history behind $\mathrm{Y} 90$ dosimetry and the difference between the aforementioned models. When applying these three models to a single case, the differences between them are further demonstrated. Each dosimetry model in clinical practice has its own benefits and limitations. Therefore, it is incumbent upon practicing interventional radiologists to be aware of these differences to optimize treatment outcomes for their patients.
\end{abstract}

Yttrium-90 radioembolization (Y90-RE) is a form of internal radiotherapy utilized for the treatment of both primary and secondary hepatic malignancies. ${ }^{1-9}$ Radioembolization, the preferred treatment nomenclature, ${ }^{10}$ is also referred to synonymously as selective internal radiation therapy. Yttrium90 microspheres are delivered directly into the hepatic arteries which are the predominant supply of the hepatic tumors. ${ }^{11}$ The mechanism of action for Y90-RE tumor treatment is radiationinduced necrosis from the transarterial administration of Y90 microspheres. ${ }^{12}$ Y90 predominantly emits $\beta$-radiation, has a 64.2-hour half-life, and delivers most of its radiation (94\%) within the first 11 days. $^{12}$ Two types of yttrium-90 microspheres are commercially available in the United States-glass microspheres, TheraSphere (Boston Scientific, Marlborough, MA) ${ }^{13}$ and resin microspheres, SIR-Spheres (Sirtex Medical Limited, Woburn, MA). ${ }^{11,14}$ The average size of resin microspheres is larger than its glass counterpart, with a median diameter of 32.5 microns (range: $20-60$ microns). Glass microspheres have a diameter range of 20 to 30 microns. ${ }^{15,16}$ The mean specific activity per sphere varies between products; glass microspheres have an activity as high as 2,500 Bq per sphere, while resin microspheres have an activity of $150 \mathrm{~Bq}$ per sphere in 3-day precalibrated format. Necessarily, the inherent differences affect the number of microspheres administered to achieve a prescribed activity. ${ }^{15,17,18}$ Multiple guidelines, such as those of National Comprehensive Cancer Network (NCCN) ${ }^{19}$ and the American Association for the Study of Liver Disease, ${ }^{20}$ consider the use of Y90-RE as a treatment option for hepatocellular carcinoma (HCC), intrahepatic cholangiocarcinoma, and hepatic metastases. ${ }^{21,22}$ Nevertheless, multiple randomized phase 3 trials such as the SIRveNIB and SARAH showed no improvement in overall survival (OS) in HCC with selective internal radiotherapy when compared with the chemotherapeutic, sorafenib. ${ }^{23-25}$ However, the failure to demonstrate superiority does not necessarily mean Y90 is equivalent to sorafenib. ${ }^{26}$ Specifically, a common criticism of many "failed" Y90 trials including SARAH and SIRveNIB is the absence of personalized dosimetry included in the trials. Moreover, post hoc dosimetry analysis of the SARAH trial demonstrated that patients with HCC who received intratumoral Y90 dose of at least $100 \mathrm{~Gy}$ had a significantly prolonged median OS of 14.1 versus 6.1 months for others. ${ }^{27}$ Additionally, the phase 2
Issue Theme Seminars in Radioembolization; Guest Editors, Robert J. Lewandowski, MD, FSIR and William Rilling, MD (c) 2021. Thieme. All rights reserved. Thieme Medical Publishers, Inc., 333 Seventh Avenue, 18th Floor, New York, NY 10001, USA
DOI https://doi.org/ 10.1055/s-0041-1732323. ISSN 0739-9529. 
DOSISPHERE-01 trial demonstrated that delivery of personalized dosimetry significantly improved objective response rates and prolonged OS in patients with locally advanced HCC, suggesting that personalized dosimetry is critical to improve outcomes in clinical practice. ${ }^{28}$ The goal of this review is to provide a brief history of dosimetry, an overview of the relevant models in practice, and a case example to illustrate clinical implications of different dosimetry models for practicing interventional radiologists and trainees.

\section{A Brief History of Dosimetry}

The first reported use of radioembolization with Y90 microspheres was to treat colorectal cancer that had metastasized to the liver in animals and two human subjects. ${ }^{12,29}$ Subsequent expansion of the technology used Y90 to treat HCC. ${ }^{30-32}$ The first attempt to perform dosimetry from Y90 delivery to the liver was in 1965, where a 10-patient clinical trial revealed the exact dosage was difficult to calculate without knowledge of the distribution of isotopes after administration. The investigators assumed a uniform distribution, ignoring the differences between distribution within tumor and nontumoral liver while admitting that to be a shortcoming of their estimations. ${ }^{33}$ In the next 20 years, the body surface area (BSA) model was created, which calculated activity to be administered in the form of resin microspheres based on BSA and later on tumor extent. ${ }^{34}$ During this time, treatment-related toxicities such as myelosuppression, pulmonary fibrosis, and gastritis were seen and believed to be related to the inability to accurately calculate radiation dosages to different compartments. To build upon creating a more accurate Y90 dosimetry model, a 15-patient trial used technetium-99 (Tc-99)-labeled macroaggregated albumin (MAA) to determine liver-lung shunt fraction (LSF) prior to glass microsphere treatment, $\mathrm{CT}$ imaging to estimate liver volume, and a posttreatment bremsstrahlung scan to confirm hepatic Y90 delivery and exclude inadvertent extrahepatic activity. This study created what is now known as the medical internal radiation dose (MIRD) model. ${ }^{35}$

Because HCC is currently the most well-studied pathology for Y90-RE dosimetry, we will focus on HCC in this review. The pathophysiology for treating HCC and other primary and metastatic liver tumors with radioembolization lies in the tumors' unique blood supply. HCC preferentially induces angiogenesis from the hepatic arterial supply instead of the portal venous system. ${ }^{36}$ In a similar way, metastatic tumors also derive the majority of their blood supply ( $80-100 \%$ for tumors $>3 \mathrm{~mm}$ ) from the hepatic arterial system. ${ }^{37}$ The tumoricidal effect of radioembolization is primarily mediated by radiation injury, and specifically through induction of indirect cellular DNA damage through free radical generation. ${ }^{38,39}$

The goal of radioembolization therapy depends on overall tumor burden and goals of care. Patients can be categorized into two treatment groups: curative intent and palliative intent. For those undergoing treatment with curative intent, there are two treatment options-radiation segmentectomy (Y90-RS) or radiation lobectomy (Y90-RL). In patients undergoing treatment with palliative intent, treatment is personalized to delay disease progression and maintain quality of life regardless of the tumor presentation as unilobar, bilobar, or with macrovascular invasion. ${ }^{40}$ To achieve these goals of care, it is necessary to understand how the dosage of radiation is calculated when performing a radioembolization to achieve the safest and most efficacious possible patient outcomes. $^{28,41}$ Currently, there are three Y90 radioembolization dosimetry models used in clinical practice: the BSA model, MIRD model, and the partition model. As a treating interventional radiologist, it is critical to understand and interpret all these models to maximize treatment goals and minimize treatment-related complications.

\section{Standard Models in Practice}

\section{Body Surface Area Model}

Commonly used for resin microspheres as the recommended model in SIR-Sphere package insert, ${ }^{42}$ the body surface model calculates the prescribed activity for each patient using only the BSA formula and the tumor burden within the targeted tissue. ${ }^{12,43}$

$$
A\left[\mathrm{~GB}_{\mathrm{q}}\right]=(\mathrm{BSA}-0.2)+\frac{v_{t}}{v_{t}+v_{n}}
$$

$A[\mathrm{GBq}]$ is the activity within the target tissue, $v_{\mathrm{t}}$ is the tumor volume, and $v_{\mathrm{n}}$ is the normal tissue volume. BSA is calculated using the Du Bois BSA formula ${ }^{44}$ :

$$
\begin{aligned}
& \text { BSA }\left(\mathrm{m}^{2}\right)=\text { weight in } \mathrm{kg}^{0.425} \\
& \times \text { height in centimeters } \\
& 0.725 \times 0.007184
\end{aligned}
$$

The BSA model is simple and easy to calculate. Despite the ease of dose calculation, two treatment contraindications to consider when using this model are greater than $20 \%$ lung shunting or greater than $30 \mathrm{~Gy}$ radiation dose absorbed to the lungs (as estimated by Tc-99-MAA scan). ${ }^{15}$ In addition, the BSA model has limited personalization and does not allow adjustment to calculate absorbed radiation dose of the tumor tissue versus surrounding nontumoral liver tissue. For large tumors/ area to be treated, the BSA model can undertreat because it artificially limits Y90 activity between 1.0 and $3.0 \mathrm{GBq} .{ }^{43}$ Additionally, there is low correlation between BSA and liver volumes, which can result in significantly lower activity concentrations in patients with larger livers. ${ }^{45}$ On the other hand, there is the potential to overdose obese patients with a relatively normal liver volume with respect to the patient's size ( - Table 1 ).

\section{Medical Internal Radiation Dose Model}

Recommended by the manufacturer of glass microspheres, the MIRD model was updated in $1975 .^{46}$ The current, clinically used MIRD model calculates administered activity using the following formula:

$$
A_{0}\left[\mathrm{~GB}_{\mathrm{q}}\right]=\frac{D[\mathrm{~Gy}] \times \text { mass of liver }[\mathrm{kg}]}{50 \times\left(1-\frac{\mathrm{LSF}}{100}\right)}
$$


Table 1 Dosimetry models, equations, and limitations

\begin{tabular}{|c|c|c|c|}
\hline & Equation & Benefits & Limitations \\
\hline$B S A$ & $A_{0}\left[\mathrm{~GB}_{\mathrm{Q}}\right]=(\mathrm{BSA}-0.2)+\frac{v_{t}}{v_{t}+v_{n}}$ & $\begin{array}{l}\text { - Simple } \\
\text { - Easy to calculate } \\
\text { - Can consider dose } \\
\text { reductions based on } \\
\text { LSF } \\
\text { - Model recommended } \\
\text { by SIRTex resin } \\
\text { microspheres }\end{array}$ & $\begin{array}{l}\text { - Limited personalization } \\
\text { - No consideration of } \\
\text { tumor dose based on } \\
\text { ratio of tumor to normal } \\
\text { liver tissue } \\
\text { - Y90 activity limited to } \\
1.0-3.0 \mathrm{GBq} \\
\text { - Tumor radiation dose is } \\
\text { unknown } \\
\text { - Possibility to undertreat }\end{array}$ \\
\hline MIRD & $A_{0}\left[\mathrm{~GB}_{\mathrm{q}}\right]=\frac{D[\mathrm{~Gy}] \times \text { mass of liver }[\mathrm{kg}]}{50 \times\left(1-\frac{\mathrm{LSF}}{100}\right)}$ & $\begin{array}{l}\text { - Simple, single model } \\
\text { - Consistent and } \\
\text { reproducible estimates }\end{array}$ & $\begin{array}{l}\text { - Does not differentiate the } \\
\text { dose given to tumor vs. } \\
\text { normal liver parenchyma } \\
\text { - Y90 microsphere } \\
\text { administration is not } \\
\text { uniform in practice } \\
\text { - Possibility to overtreat }\end{array}$ \\
\hline Partition & $A_{0}\left[\mathrm{~GB}_{\mathrm{q}}\right]=\frac{\left(D[\mathrm{~Gy}] \times \frac{T}{N} \times \text { tumor mass }[\mathrm{kg}]\right)}{(50 \times(1-\mathrm{LSF}))}$ & $\begin{array}{l}\text { - Accounts for different } \\
\text { compartments } \\
\text { - Allows calculation of } \\
\text { tumor, nontumor, and } \\
\text { lung dosages }\end{array}$ & $\begin{array}{l}\text { - More complex to calculate } \\
\text { - Relies on Tc-99-MAA as } \\
\text { surrogate for Y90 } \\
\text { microsphere } \\
\text { biodistribution } \\
\text { - Assumes uniform } \\
\text { distribution in each } \\
\text { compartment }\end{array}$ \\
\hline
\end{tabular}

Abbreviations: BSA, body surface area; LSF, lung shunt fraction; MAA, macroaggregated albumin; MIRD, medical internal radiation dose.

$A_{0}[\mathrm{GBq}]$ represents the activity to be administered, $D[\mathrm{~Gy}]$ is the dose delivered into the liver lobe/segment in Gray, and 50 is a rounded constant derived from the Y90 isotope characteristics. ${ }^{40}$ Further information on the derivation of the MIRD formula is covered elsewhere. ${ }^{40,47,48}$

The MIRD model is a single-compartment model that assumes uniform activity distribution within the target tissue. However, the targeted tissue contains tumor and nontumor liver parenchyma; this is precisely the major limitation of this model. In settings of severe cirrhosis or emphysema, this model can underestimate dose to the liver or lung because the model presumes radiation absorption will be the same as normal liver or lung tissue, ${ }^{48}$ potentially leading to overtreatment of patients. ${ }^{49}$ Benefits of the MIRD model include its ease of calculation and its consistent and reproducible dose estimates. $^{47}$

\section{Partition Model}

Dependent on Tc-99m-MAA single-photon emission computed tomography (SPECT)/CT modeling, the partition model is more complex, incorporating tumor, nontumor liver, and lung components. This model is hypothesized to minimize radiation-induced hepatotoxicity compared with BSA and MIRD models. ${ }^{50}$

$$
A_{0}\left[\mathrm{~GB}_{\mathrm{q}}\right]=/ \frac{\left(D[\mathrm{~Gy}] \times \frac{T}{N} \times \text { tumor mass }[\mathrm{kg}]\right)}{(50 \times(1-\mathrm{LSF}))}
$$

$A_{0}[G B q]$ represents the activity in the targeted liver tissue, $D[\mathrm{~Gy}]$ is the desired tumor dose in Gray, $T / N$ is the relative uptake of tumor versus normal liver, and LSF is the lung shunt fraction. This model is technically more complex and incorporates multiple compartments (liver, tumor, and lung), making it more accurate to use. This model allows for activity administration in which tumor, nontumor liver, or lung doses can be separately calculated and used as the thresholds. However, the Partition model is limited by the use of Tc-99-MAA due to inconsistencies in biodistribution compared with Y90 microspheres and also from variability in catheter position upon dose administration. ${ }^{51}$ Additionally, the model assumes uniform distribution of the activity in each compartment, ${ }^{52}$ which is not an accurate assumption.

\section{Case Example: Dosimetry in Practice}

\section{Recommended General Planning and Treatment Algorithm}

At our institution, patients first undergo vascular mapping and Tc-99m-MAA shunt studies using planar and SPECT/CT to determine LSF, extrahepatic activity, and $T / N$ if the partition model is being used. Additionally, cone beam CT (CBCT) is utilized during the mapping study to ensure complete tumor perfusion is through the subselected vessel(s). Coiling/plugging is performed as needed to minimize the risk of nontarget embolization. It is critical to ensure complete tumor perfusion is identified on mapping to enable proper treatment planning. Preferably, the circumstances of Tc-99m- 
MAA administration are replicated for the planned therapy including use of the same microcatheter and delivery from the same vascular location. After the desired administered activity is calculated based on the treatment intent and the dosimetry model used, the patient is brought back to interventional radiology for the therapy session. From the same microcatheter position (or positions of split activity administration) that the MAA was administered and again after confirming complete perfusion of the tumor both on mapping CBCT and MAA SPECT/CT, prescribed Y90 activity will be administered. Patient will then undergo Y90 bremsstrahlung SPECT/CT again to ensure complete targeting of the tumor and absence of nontarget embolization. Post-Y90 administration dosimetry can also be performed to ensure delivery of treatment goal doses to the tumor and nontumoral liver parenchyma.

\section{Patient Case}

A 65-year-old man with a past medical history of hepatitis Cinduced cirrhosis presented with a $2.9-\mathrm{cm}$ HCC tumor in segment 6 of his liver. Based on laboratory, imaging, and clinical assessment, he was an orthotopic liver transplant candidate classified as Child-Pugh A, Eastern Cooperative Oncology Group score 0 (ECOG-0), and Barcelona Clinic Liver Cancer stage A (BCLC-A). He was referred to the interventional radiology clinic for bridging therapy and $\mathrm{Y} 90$ was thought to be the most appropriate treatment for this patient. Baseline MRI demonstrated an avidly enhancing lesion with washout in segment 6 (-Fig. 1a). On mapping angiography (-Fig. 1b), the
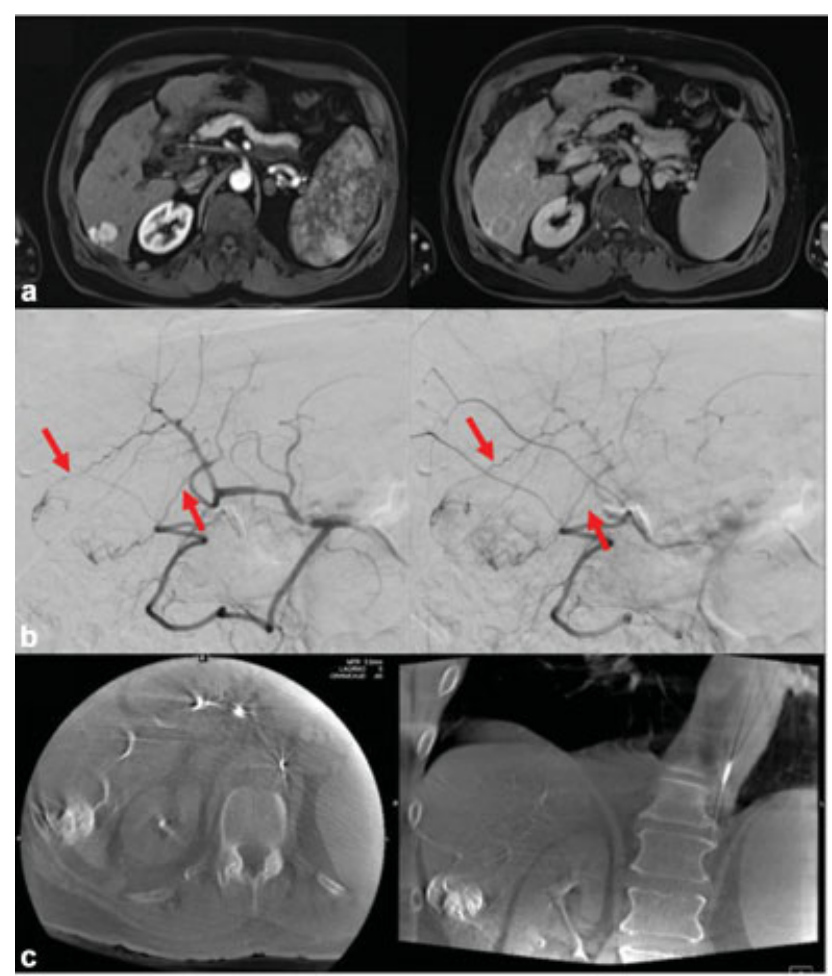

Fig. 1 (a) Pretreatment, avidly enhancing hepatocellular carcinoma tumor seen in segment 6 . (b) The red arrows denote the feeding arteries visualized by selective right hepatic angiography. (c) Cone beam $C T$ (CBCT)-use of $C B C T$ ensures complete coverage of the tumor from the location of the microcatheter where macroaggregated albumin is to be administered.

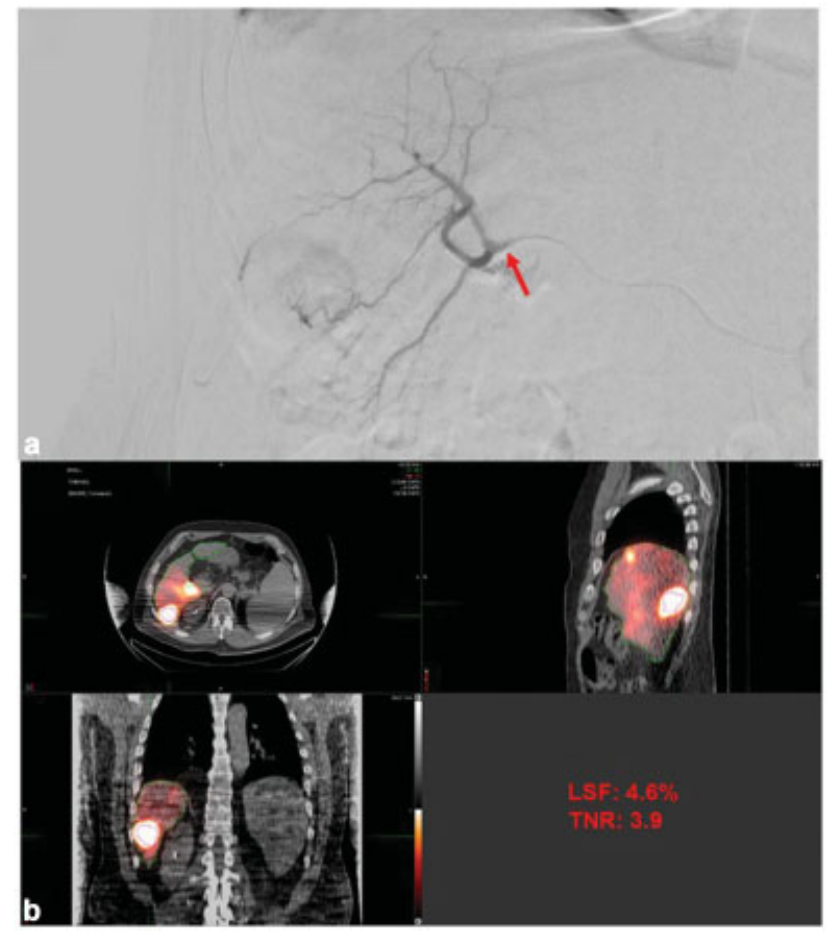

Fig. 2 (a) Tc-99-macroaggregated albumin (MAA) injection and (b) Tc-99-MAA single-photon emission computed tomography confirm complete coverage of the targeted tumor with no extrahepatic activity.

patient was noted to have a hypervascular tumor supplied by two small branches of the right hepatic artery, one arising from the anterior right hepatic artery and one from the posterior. These branches were not amenable to selective catheterization due to size and risk of vasospasm. The decision was made to plan the treatment to the entire right lobe. CBCT was then performed (-Fig. 1c) prior to MAA administration (-Fig. 2a) to ensure complete coverage of the tumor and absence of potential nontarget embolization. Tc-99-MAA was administered from the microcatheter location where $\mathrm{CBCT}$ was performed. The Tc-99-MAA SPECT study confirmed complete coverage of the targeted tumor with no extrahepatic activity ( - Fig. 2b). The LSF was calculated to be $4.6 \%$ with a Tumor to Normal Ratio (TNR) of 3.9.

Treatment was planned using MIRD model with delivery of $80 \mathrm{~Gy}$ to the right lobe using SIR-Sphere. The treatment plan was based on the SARAH trial data, which demonstrated that tumor dosage of $100 \mathrm{~Gy}$ or more improves tumor response and prolongs survival. ${ }^{53}$ Given the hypervascular nature of the tumor, greater than $100 \mathrm{~Gy}$ was projected to be delivered to the tumor. Accordingly, $2.2 \mathrm{GBq}$ of activity was administered to the right hepatic artery.

Prescribed Y90 activity was then administered from the same microcatheter position from which Tc-99-MAA was administered and using the same type of microcatheter (2.8 Fr Progreat; Terumo Medical Corporation, Tokyo, Japan). The patient then underwent confirmatory Y90 SPECT/CT. Postadministration dosimetry using MIM SurePlan (MIM Software, Cleveland, $\mathrm{OH}$ ) was performed to ensure adequate dose

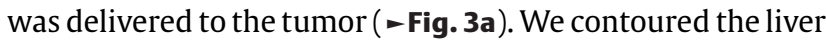




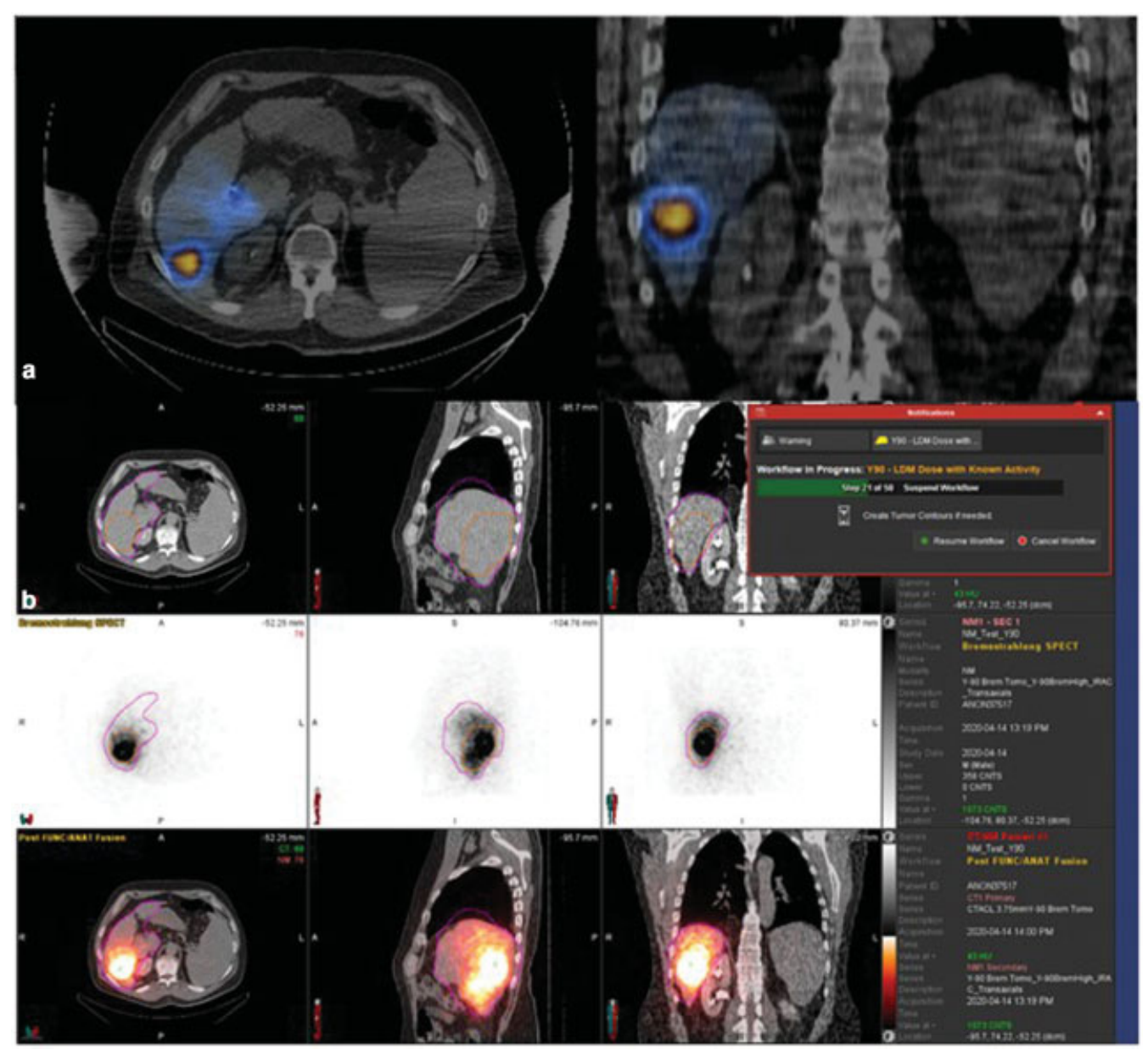

Fig. 3 Actual treatment: (a) Bremsstrahlung single-photon emission computed tomography (SPECT) calculation of administered activity (b) Posttreatment Y90 SPECT/CT confirming Y90 administration.

and tumor on contrast-enhanced MRI or CT which then was fused to the Y90 bremsstrahlung SPECT/CT ( - Fig. 3b). The calculated dose delivered to the tumor was $303 \mathrm{~Gy}$, while the dose to the nontumoral liver was $73 \mathrm{~Gy}$, which is above the recommended target dose to nontumoral liver when treating with resin microspheres. ${ }^{54}$ Dynamic contrast-enhanced MRI 6 weeks posttherapy demonstrated complete response in the targeted tumor ( - Fig. 4). At 6-month follow-up, the patient continued to have non-viable treated tumor with no treatment-related toxicity.

- Table 2 demonstrates the projected differences in dose delivered to each compartment (i.e. tumor, non-tumoral

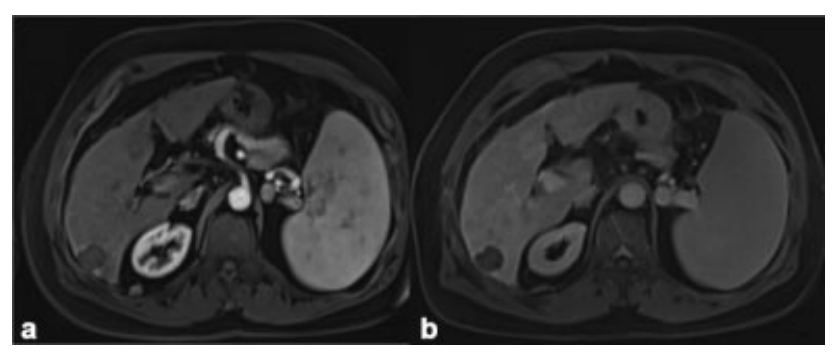

Fig. 4 Six weeks posttherapy, magnetic resonance imaging demonstrates complete response seen on both arterial (a) and portal venous (b) phases of study with preserved liver function. liver and lung), had we used BSA model, MIRD model with the goal of $120 \mathrm{~Gy}$ to the perfused liver segment/lobe, and partition model with the goal of $200 \mathrm{~Gy}$ to the tumor.

Using MIRD model with the goal of $120 \mathrm{~Gy}$ to the infused right liver lobe, $424 \mathrm{~Gy}$ would be delivered to the tumor which would be considered over treatment for HCC treated with resin microspheres. More importantly, nontumoral liver dose of $109 \mathrm{~Gy}$ would significantly increase the risk of hepatotoxicity given the size of the area treated. Had we used the BSA model, which is the recommended model to be used for resin microspheres, $183 \mathrm{~Gy}$ would be delivered to the tumor which would be probably tumoricidal based on available evidence ${ }^{27}$ and 47 Gy to the nontumoral liver which is considered a safe threshold by many experts. On the other hand, had we used the partition model, we could ensure delivery of $200 \mathrm{~Gy}$ to the tumor while delivering $51 \mathrm{~Gy}$ to the liver which is probably the upper limits of nontumoral liver dose to minimize significant hepatotoxicity. ${ }^{54,55}$ Finally, using the actual treatment planning strategy employed in this case, we probably overtreated the tumor which means delivering higher than desired dose to the nontumoral liver which could cause liver toxicity.

In conclusion, as illustrated in the example earlier, and throughout this article, each Y90 dosimetry model in current 
Table 2 Prescribed activity and dose delivered to each compartment using different dosimetry models

\begin{tabular}{|l|l|l|l|l|l|}
\hline \multicolumn{2}{|l|}{ Actual administered activity and dose to different compartments } \\
\hline & $\begin{array}{l}\text { Actual administered } \\
\text { activity }\end{array}$ & Tumor dose & $\begin{array}{l}\text { Nontumor } \\
\text { liver dose }\end{array}$ & Lung dose & Notes \\
\hline Mean activity (range) & $2.2 \mathrm{GBq}$ & $\begin{array}{l}303 \mathrm{~Gy} \\
(925-0 \mathrm{~Gy})\end{array}$ & $\begin{array}{l}73 \mathrm{~Gy} \\
(326-0 \mathrm{~Gy})\end{array}$ & $5.1 \mathrm{~Gy}$ & \\
\hline \multicolumn{5}{|l|}{ Projected dose to different compartments using different dosimetry models } \\
\hline & $\begin{array}{l}\text { Calculated } \\
\text { administered activity }\end{array}$ & Tumor dose & $\begin{array}{l}\text { Nontumor } \\
\text { liver dose }\end{array}$ & Lung dose & Notes \\
\hline BSA & $1.4 \mathrm{GBq}$ & $183 \mathrm{~Gy}$ & $47 \mathrm{~Gy}$ & $3.7 \mathrm{~Gy}$ & $\begin{array}{l}\text { Height: } 5^{\prime} 10^{\prime \prime} \\
\text { Weight: } 78 \mathrm{~kg}\end{array}$ \\
\hline $\begin{array}{l}\text { MIRD w/ 120 Gy to } \\
\text { the perfused lobe }\end{array}$ & $3.4 \mathrm{GBq}$ & $424 \mathrm{~Gy}$ & $109 \mathrm{~Gy}$ & $8.5 \mathrm{~Gy}$ & Treated liver: $1,350 \mathrm{cc}$ \\
\hline Partition model & $1.8 \mathrm{GBq}$ & $200 \mathrm{~Gy}$ & $51 \mathrm{~Gy}$ & $4 \mathrm{~Gy}$ & \\
\hline
\end{tabular}

Abbreviations: BSA, body surface area; MIRD, medical internal radiation dose.

clinical practice has pros and cons with significant clinical implications. It is incumbent upon practicing interventional radiologists to know the clinically significant differences between these models to ensure the best treatment outcomes for their patients.

\section{Conflicts of Interest}

N.K. receives funding from SIRTEX Medical. R.T.G. discloses a relationship with Sirtex as a proctor, speaker, and consultant. R.G. is a proctor and consultant for Sirtex. All other authors declare no conflict of interest.

\section{References}

1 Ahmadzadehfar H, Biersack H-J, Ezziddin S. Radioembolization of liver tumors with yttrium-90 microspheres. Semin Nucl Med 2010;40(02):105-121

2 Kennedy A, Bester L, Salem R, Sharma RA, Parks RW, Ruszniewski PNET-Liver-Metastases Consensus Conference. Role of hepatic intra-arterial therapies in metastatic neuroendocrine tumours (NET): guidelines from the NET-Liver-Metastases Consensus Conference. HPB (Oxford) 2015;17(01):29-37

3 Salem R, Lewandowski RJ, Mulcahy MF, et al. Radioembolization for hepatocellular carcinoma using Yttrium-90 microspheres: a comprehensive report of long-term outcomes. Gastroenterology 2010;138(01):52-64

4 Wang S-C, Bester L, Burnes JP, et al. Clinical care and technical recommendations for ${ }^{90}$ yttrium microsphere treatment of liver cancer. J Med Imaging Radiat Oncol 2010;54(03):178-187

5 Garlipp B, Gibbs P, Van Hazel GA, et al. Secondary technical resectability of colorectal cancer liver metastases after chemotherapy with or without selective internal radiotherapy in the randomized SIRFLOX trial. Br J Surg 2019;106(13):1837-1846

6 Kalinowski M, Dressler M, König A, et al. Selective internal radiotherapy with yttrium-90 microspheres for hepatic metastatic neuroendocrine tumors: a prospective single center study. Digestion 2009;79(03):137-142

7 Mulcahy MF, Lewandowski RJ, Ibrahim SM, et al. Radioembolization of colorectal hepatic metastases using yttrium-90 microspheres. Cancer 2009;115(09):1849-1858

8 Andrews JC, Walker SC, Ackermann RJ, Cotton LA, Ensminger WD, Shapiro B. Hepatic radioembolization with yttrium-90 containing glass microspheres: preliminary results and clinical follow-up. J Nucl Med 1994;35(10):1637-1644
9 Herba MJ, Thirlwell MP. Radioembolization for hepatic metastases. Semin Oncol 2002;29(02):152-159

10 Salem R, Lewandowski RJ, Gates VL, et al; Technology Assessment Committee; Interventional Oncology Task Force of the Society of Interventional Radiology. Research reporting standards for radioembolization of hepatic malignancies. J Vasc Interv Radiol 2011; 22(03):265-278

11 Lewandowski RJ, Geschwind J-F, Liapi E, Salem R. Transcatheter intraarterial therapies: rationale and overview. Radiology 2011; 259(03):641-657

12 Tong AKT, Kao YH, Too CW, Chin KF, Ng DC, Chow PK. Yttrium-90 hepatic radioembolization: clinical review and current techniques in interventional radiology and personalized dosimetry. $\mathrm{Br} \mathrm{J}$ Radiol 2016;89(1062):20150943

13 Lau W-Y, Leung WT, Ho S, et al. Treatment of inoperable hepatocellular carcinoma with intrahepatic arterial yttrium-90 microspheres: a phase I and II study. Br J Cancer 1994;70(05):994-999

14 Dancey JE, Shepherd FA, Paul K, et al. Treatment of nonresectable hepatocellular carcinoma with intrahepatic 90Y-microspheres. J Nucl Med 2000;41(10):1673-1681

15 SirTex About SIR-Spheres microspheres. Accessed June 30, 2021 at: https://www.sirtex.com/us/clinicians/about-sir-spheresmicrospheres/

16 TheraSphere ${ }^{\mathrm{TM}}$ Y-90 Glass Microspheres - Boston Scientific. Accessed June 30, 2021 at: https://www.bostonscientific. com/content/gwc/en-US/products/cancer-therapies/therasphere-y90-glass-microspheres.html

17 Boston Scientific TheraSphere Y-90 Glass Microspheres. Accessed June 30, 2021 at: https://www.bostonscientific.com/en-US/ products/cancer-therapies/therasphere-y90-glass-microspheres/ product-specifications.html

18 Kis B, El-Haddad G, Sheth RA, et al. Liver-directed therapies for hepatocellular carcinoma and intrahepatic cholangiocarcinoma. Cancer Contr 2017;24(03):1073274817729244

19 National Comprehensive Cancer Network Inc. NCCN guidelines version 2.2021 hepatobiliary cancer. Natl Compr Cancer Netw 2021;2:MS21-MS25

20 Heimbach JK, Kulik LM, Finn RS, et al. AASLD guidelines for the treatment of hepatocellular carcinoma. Hepatology 2018;67(01): 358-380

21 NCCN Clinical Practice Guidelines in Oncology (NCCN Guidelines $®$ ) Hepatobiliary Cancers (Version 4.2019). https://www.nccn.org/ professionals/physician_gls/pdf/hepatobiliary.pdf. Date Accessed 9/6/2021

22 EASL Clinical Practice Guidelines: management of hepatocellular carcinoma. J Hepatol 2018;69(01):182-236 
23 Chow PKH, Gandhi M, Tan SB, et al; Asia-Pacific Hepatocellular Carcinoma Trials Group. SIRveNIB: selective internal radiation therapy versus sorafenib in Asia-Pacific patients with hepatocellular carcinoma. J Clin Oncol 2018;36(19):1913-1921

24 Ricke J, Klümpen HJ, Amthauer H, et al. Impact of combined selective internal radiation therapy and sorafenib on survival in advanced hepatocellular carcinoma. J Hepatol 2019;71(06): 1164-1174

25 Vilgrain V, Pereira H, Assenat E, et al; SARAH Trial Group. Efficacy and safety of selective internal radiotherapy with yttrium-90 resin microspheres compared with sorafenib in locally advanced and inoperable hepatocellular carcinoma (SARAH): an open-label randomised controlled phase 3 trial. Lancet Oncol 2017;18(12): 1624-1636

26 Llovet JM, Finn RS. Negative phase 3 study of ${ }^{90} \mathrm{Y}$ microspheres versus sorafenib in HCC. Lancet Oncol 2018;19(02):e69

27 Hermann A-L, Dieudonné A, Ronot M, et al; SARAH Trial Group. Relationship of tumor radiation-absorbed dose to survival and response in hepatocellular carcinoma treated with transarterial radioembolization with ${ }^{90} \mathrm{Y}$ in the SARAH Study. Radiology 2020; 296(03):673-684

28 Garin E, Tselikas L, Guiu B, et al; DOSISPHERE-01 Study Group. Personalised versus standard dosimetry approach of selective internal radiation therapy in patients with locally advanced hepatocellular carcinoma (DOSISPHERE-01): a randomised, multicentre, open-label phase 2 trial. Lancet Gastroenterol Hepatol 2021;6(01):17-29

29 Ariel IM. Radioactive isotopes for adjuvant cancer therapy; animal experimentation and preliminary results in human application. Arch Surg 1964;89:244-249

30 Ariel IM, Padula G. Treatment of asymptomatic metastatic cancer to the liver from primary colon and rectal cancer by the intraarterial administration of chemotherapy and radioactive isotopes. J Surg Oncol 1982;20(03):151-156

31 Ariel IM, Padula G. Treatment of symptomatic metastatic cancer to the liver from primary colon and rectal cancer by the intraarterial administration of chemotherapy and radioactive isotopes. J Surg Oncol 1978;10(04):327-336

32 Grady ED, Nolan TR, Crumbley AJ, Larose JH, Cheek WV. Internal hepatic radiotherapy: II. Intra-arterial radiocolloid therapy for hepatic tumors. Am J Roentgenol Radium Ther Nucl Med 1975; 124(04):596-599

33 Ariel IM. Treatment of inoperable primary pancreatic and liver cancer by the intra-arterial administration of radioactive isotopes (Y90 radiating microspheres). Ann Surg 1965;162:267-278

34 Mantravadi RV, Spigos DG, Tan WS, Felix EL. Intraarterial yttrium 90 in the treatment of hepatic malignancy. Radiology 1982;142 (03):783-786

35 Herba MJ, Illescas FF, Thirlwell MP, et al. Hepatic malignancies: improved treatment with intraarterial Y-90. Radiology 1988;169 (02):311-314

36 Matsui O. Imaging of multistep human hepatocarcinogenesis by CT during intra-arterial contrast injection. Intervirology 2004;47 (3-5):271-276

37 Lien WM, Ackerman NB. The blood supply of experimental liver metastases. II. A microcirculatory study of the normal and tumor vessels of the liver with the use of perfused silicone rubber. Surgery 1970;68(02):334-340

38 Arii S, Teramoto K, Kawamura T. Current progress in the understanding of and therapeutic strategies for ischemia and reperfusion injury of the liver. J Hepatobiliary Pancreat Surg 2003;10(03): 189-194
39 Elkind MM. Modifiers of radiation response in tumor therapy: strategies and expectations. Int J Radiat Oncol Biol Phys 1982;8 (01):89-100

40 Villalobos A, Soliman MM, Majdalany BS, et al. Yttrium-90 radioembolization dosimetry: what trainees need to know. Semin Intervent Radiol 2020;37(05):543-554

41 Kokabi N, Galt JR, Xing M, et al. A simple method for estimating dose delivered to hepatocellular carcinoma after yttrium-90 glass-based radioembolization therapy: preliminary results of a proof of concept study. J Vasc Interv Radiol 2014;25(02): $277-287$

42 Sirtex - Instructions for Use Accessed June 30, 2021 at: https:// www.sirtex.com/us/clinicians/instructions-for-use/

$43 \mathrm{Kao}$ YH, Tan EH, Ng CE, Goh SW. Clinical implications of the body surface area method versus partition model dosimetry for yttrium-90 radioembolization using resin microspheres: a technical review. Ann Nucl Med 2011;25(07):455-461

44 Du Bois D, Du Bois EF. A formula to estimate the approximate surface area if height and weight be known. 1916. Nutrition 1989; 5(05):303-311, discussion 312-313

45 Grosser OS, Ulrich G, Furth C, et al. Intrahepatic activity distribution in radioembolization with yttrium-90-labeled resin microspheres using the body surface area method-a less than perfect model. J Vasc Interv Radiol 2015;26(11): $1615-1621$

46 Snyder W, Ford M, Warner G, W. S. MIRD Pamphlet 11: S, Absorbed Dose per Unit Cumulated Activity for Selected Radionuclides and Organs. Society of Nuclear Medicine 1975

47 Gulec SA, Mesoloras G, Stabin M. Dosimetric techniques in 90Ymicrosphere therapy of liver cancer: the MIRD equations for dose calculations. J Nucl Med 2006;47(07):1209-1211

48 Toohey RE, Stabin MG, Watson EE. The AAPM/RSNA physics tutorial for residents: internal radiation dosimetry: principles and applications. Radiographics 2000;20(02):533-546, quiz 531-532

49 Sarwar A, Kudla A, Weinstein JL, et al. Yttrium-90 radioembolization using MIRD dosimetry with resin microspheres. Eur Radiol 2021;31(03):1316-1324

50 Gnesin S, Canetti L, Adib S, et al. Partition model-based ${ }^{99 \mathrm{~m}} \mathrm{Tc}$ MAA SPECT/CT predictive dosimetry compared with 90Y TOF $\mathrm{PET} / \mathrm{CT}$ posttreatment dosimetry in radioembolization of hepatocellular carcinoma: a quantitative agreement comparison. J Nucl Med 2016;57(11):1672-1678

51 Thomas MA, Mahvash A, Abdelsalam M, Kaseb AO, Kappadath SC. Planning dosimetry for ${ }^{90} \mathrm{Y}$ radioembolization with glass microspheres: Evaluating the fidelity of ${ }^{99 \mathrm{~m}}$ Tc-MAA and partition model predictions. Med Phys 2020;47(10):5333-5342

52 Spahr N, Schilling P, Thoduka S, Abolmaali N, Schenk A. Predictive SIRT dosimetry based on a territorial model. EJNMMI Phys 2017;4 (01):25

53 Palmer DH, et al. Selection of patients with hepatocellular carcinoma for selective internal radiation therapy based on tumour burden and liver function: a post-hoc analysis of the SARAH trial. Ann Oncol 2019;30:v282

54 Levillain H, Bagni O, Deroose CM, et al. International recommendations for personalised selective internal radiation therapy of primary and metastatic liver diseases with yttrium-90 resin microspheres. Eur J Nucl Med Mol Imaging 2021;48(05): $1570-1584$

55 Strigari L, Sciuto R, Rea S, et al. Efficacy and toxicity related to treatment of hepatocellular carcinoma with 90Y-SIR spheres: radiobiologic considerations. J Nucl Med 2010;51(09):1377-1385 